\title{
Dinâmica das Relações Interacionais em Fóruns de Discussão em um Curso de Graduação a Distância Representada por Sociogramas
}

${ }^{1}$ Universidade Estadual do Ceará/Universidade Aberta do Brasil. Av. Dr. Silas Munguba 1700, Campus do Itaperi-Fortaleza- Ceará- Brasil. germana.paixao@uece.br

\section{Resumo}

Neste trabalho, analisa-se a dinâmica das relações entre alunos, professores e tutores em fóruns de discussão de um curso de graduação a distância em Ciências Biológicas. Para isso, o nível de interação foi observado em fóruns de discussão de quatro disciplinas curriculares e representadas por sociogramas elaborados com 0 software Pajek ${ }^{\circledR}$. Percebeu-se que o aluno desempenha papel central nas discussões e na construção do processo de ensino-aprendizagem e que sua participação nas disciplinas se torna progressivamente mais autônoma ao longo do curso. Observouse, ainda, que a quantidade de participações nem sempre está diretamente relacionada à qualidade delas, já que os alunos que mais postaram comentários nem sempre geraram interações significativas. Logo, é possível inferir que os sociogramas são ferramentas importantes para a interpretação dos dados de interação e a avaliação de participação de alunos, professores e tutores em fóruns de discussão. 
Palavras-chave: Educação a distância, Interações, Sociograma.

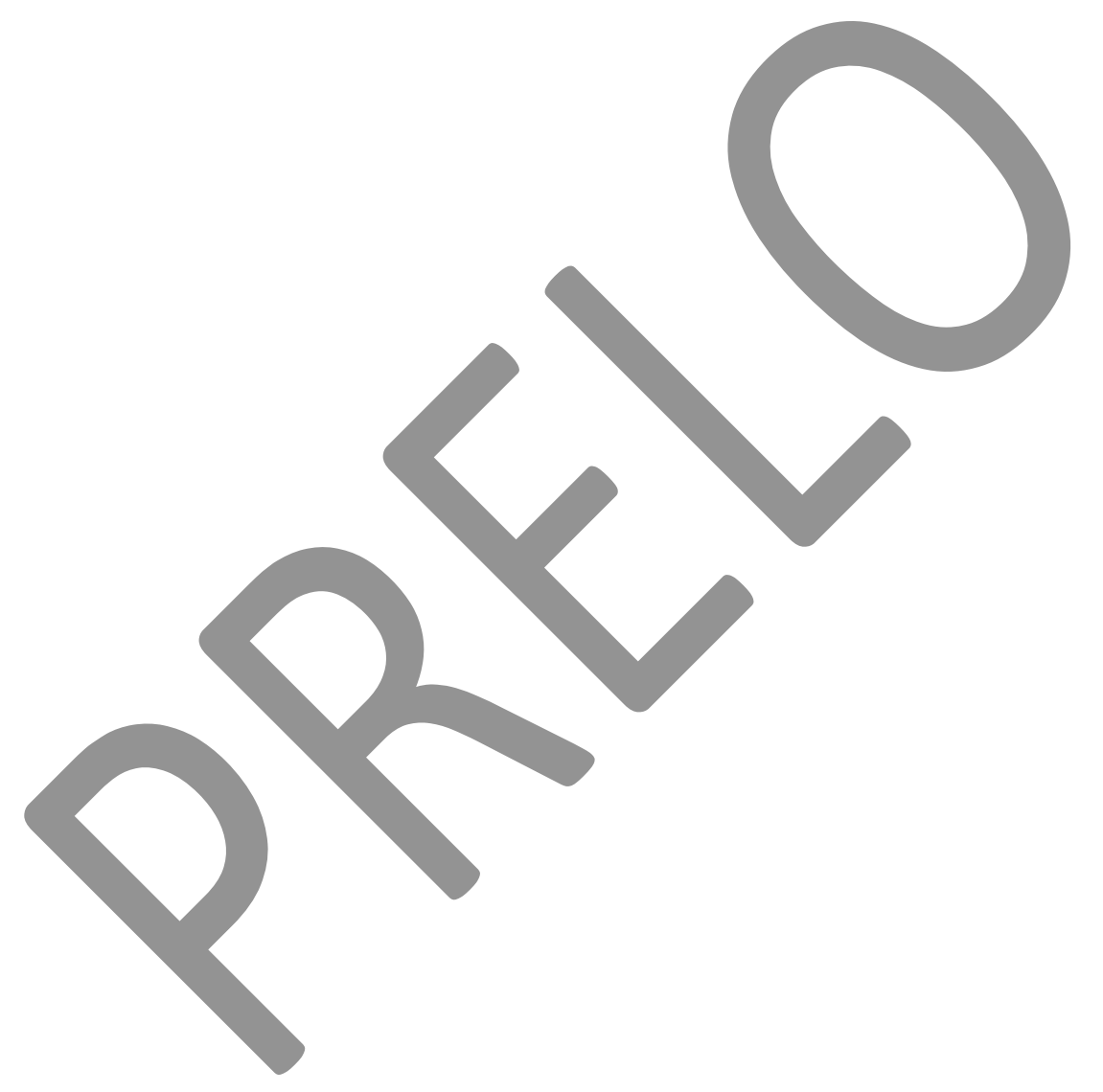




\title{
Dynamics of the Interactions in Discussion Forums of an Undergraduate Distance Education Course Represented by Sociograms
}

\begin{abstract}
The objective of this work was to analyze the interactive processes among students, teachers and tutors in interaction forums of a course in biological sciences. For this, the level of social interaction was observed in discussion forums of four curricular subjects, represented by sociograms prepared with the Pajek ${ }^{\circledR}$ software. The results revealed that the students played a central role in the discussions and the construction of the learning-teaching process and that their participation in the modules became progressively more autonomous as time passed. The level of participation was not always directly related to the quality, since the students who posted most comments in the forums did not always generate significant interactions. Therefore, it is possible to infer that sociograms are important tools for data interpretation and evaluation of participation of students, teachers and tutors in discussion forums.
\end{abstract}

Keywords: Distance education, Interactions, Sociogram. 


\section{Introdução}

Cada vez mais, observa-se que o processo educacional está sendo realizado com o auxílio da tecnologia, em que professor e aluno não precisam estar no mesmo espaço físico e ao mesmo tempo para trocar informações (CARVALHO et al., 2017), podendo construir o conhecimento em um Ambiente Virtual de Aprendizagem (AVA). Isso permite a colaboração, participação, organização e inovação no processo de ensino-aprendizagem (ABEGG et al., 2010). Além disso, as ferramentas tecnológicas possibilitam que a interação ocorra entre todas as partes envolvidas, colaborando para o desenvolvimento da autonomia de cada sujeito.

Em Educação a Distância (EaD), existem várias definições para interação, com abordagem mais direta e/ou mais global. Primo (2007) discute os conceitos de interação reativa e interação mútua. O primeiro conceito refere-se a uma interação linear e fechada, sem haver grande preocupação com o contexto. Nela ocorre um estímulo, como uma pergunta, e em seguida, há uma resposta (reação), ou seja, uma relação de causa e efeito. Já a interação mútua é um "sistema aberto" com a construção, a negociação e a cooperação de informações em um fluxo dinâmico, com a formação do conhecimento em um contexto problematizado e atualizado.

Assim, a interação mútua pode ocorrer nos AVA, especialmente por meio dos fóruns de discussão, que permitem a postagem de vários recursos educacionais, como artigos, imagens e vídeos, e o desenvolvimento da relação entre aluno, professor, tutor e conteúdo didático (ALENCAR \& NETTO, 2011; SANTOS, BAEZ\&SOUZA, 2018).

Dillenbourg (2003) salienta que, nos AVA, os estudantes não estão restritos a consultar as informações disponibilizadas pelo curso; eles se tornam produtores da informação. Sendo esse um dos aspectos que mais diferenciam a modalidade a distância da modalidade presencial, com ênfase ao trabalho autônomo do aprendente (SANTOS, 2015).

A socialização entre os integrantes de um curso é de extrema importância, visto que pode proporcionar e influenciar o compartilhamento do conhecimento, promovendo o desenvolvimento de uma inteligência coletiva (CORTELAZZO, 2010), Além de possibilitar o desenvolvimento de algumas atitudes esperadas para um aluno da modalidade a distância como: autonomia, flexibilização do tempo e do local de participação, interação e participação mais ativa na construção do conhecimento. 
Os sociogramas são técnicas sociométricas empregadas para facilitar a compreensão das relações entre indivíduos de um mesmo grupo ou entre grupos (VAZ, 2009). As métricas de centralidade permitem identificar como ocorre o acesso e a disseminação das informações ao longo da interação entre os sujeitos participantes. Dessa forma, o emprego de sociogramas na EaD pode proporcionar informações gráficas e detalhadas acerca das relações sociais entre os participantes do curso, instrumentalizando professores e tutores para a adoção de medidas preventivas na promoção da socialização e a interação mais eficientes dos alunos.

Na sala de aula virtual, os papéis assumidos no grupo são diferentes daqueles das aulas presenciais, sendo necessário desenvolver habilidades e competências específicas, como "[...] priorizar ações que busquem a interlocução entre professores, alunos e conteúdos/informações disponíveis no ambiente, o fortalecimento da percepção de vínculo [...]" (BELUCE \& OLIVEIRA, 2016).

Neste ínterim, o presente trabalho objetivou analisar a dinâmica das relações interacionais entre alunos, professores e tutores em fóruns de interação de um curso de graduação em Ciências Biológicas a distância a partir de sociogramas.

\section{Metodologia}

Trata-se de um estudo observacional descritivo, do tipo estudo de caso, com abordagens qualitativa e quantitativa (YIN, 2010). A pesquisa foi desenvolvida com a coleta de dados junto ao AVA Moodle 2.9 do curso de Licenciatura em Ciências Biológicas - BIOEaD - UECE/UAB, em funcionamento no polo de Beberibe-CE. Realizou-se a Análise Exploratória de Redes Sociais (AERS) idealizada por Noory,Mrvar e Batagelj(2005), que considera as relações sociais entre os atores, permitindo a delimitação de grupos.

As redes de interação contemplaram quatro fóruns de discussão dos quais participaram tutores, alunos e professores formadores. Foram escolhidas as disciplinas: Microbiologia, Biologia Evolutiva, Estágio Supervisionado do Ensino Fundamental (ESEF) e Estágio Supervisionado do Ensino Médio II (ESEM II), sendo as duas primeiras relacionadas a conteúdos específicos de Biologia e duas últimas direcionadas à experiência docente. As disciplinas de Microbiologia e ESEF fazem parte do $5^{\circ}$ semestre do curso, enquanto as disciplinas Biologia Evolutiva e ESEM II são do 70 semestre do fluxo curricular. Logo, os alunos foram acompanhados em disciplinas 
que ocorreram com um ano de intervalo entre elas, sendo as duas primeiras cursadas logo após a primeira metade do curso e as duas últimas no penúltimo semestre do curso, que tem, no total, 8 semestres letivos.

O critério de inclusão foram as disciplinas com maior número de postagens, visando analisar a interação entre os membros por meio de diálogos, culminando com a construção de sociogramas (VAZ, 2009). Apesar de os integrantes da equipe de suporte técnico e de a coordenação também estarem inseridos na sala virtual do curso, eles foram excluídos, em virtude de suas interações configurarem-se como pontuais e de escassa interação social, direcionadas, geralmente, para sanar problemas técnicos e administrativos.

Os dados de comunicação entre tutores, professores e estudantes nos fóruns temáticos das disciplinas foram obtidos por meio de consultas ao AVA Moodle 2.9 e transformados em dados em rede pelo software Pajek ${ }^{\circledR}$, por meio do qual é possível elaborar sociogramas com base em códigos criados a partir das participações e das interações de cada membro. Para facilitar a compreensão de alguns termos que foram utilizados para explicar as interações, sintetizamos no Quadro 1, a seguir.

Quadro 1: Termos utilizados para explicar a metodologia e suas definições

\begin{tabular}{|c|l|}
\hline \multicolumn{1}{|c|}{ Termo } & \multicolumn{1}{|c|}{ Definição } \\
\hline Comentário gerador & $\begin{array}{l}\text { Ponto de partida de uma discussão. Gera, } \\
\text { inicia a discussão. }\end{array}$ \\
\hline Comentário resposta & $\begin{array}{l}\text { Comentário realizado a partir do comentário } \\
\text { gerador. Responde ou comenta o primeiro. }\end{array}$ \\
\hline Participação & $\begin{array}{l}\text { É considerada participação toda e qualquer } \\
\text { postagem, independentemente de ter gerado } \\
\text { discussão. Não é identificada no sociograma. }\end{array}$ \\
\hline Interações efetivas & $\begin{array}{l}\text { Somente são consideradas interações } \\
\text { efetivas aquelas que geraram discussão, ou } \\
\text { seja, quando um comentário gerador foi } \\
\text { respondido/comentado. Somente as } \\
\text { interações efetivas são consideradas para a } \\
\text { elaboração dos sociogramas. }\end{array}$ \\
\hline
\end{tabular}

Fonte: Elaborado pelos próprios autores. 
Nos sociogramas, foram consideradas somente as intervenções que geraram interações entre os participantes do fórum, ou seja, as interações que respondem ou comentam intervenções já feitas por outros indivíduos ou intervenções que geraram uma discussão. As intervenções que somente responderam ao questionamento central do fórum, mas que não geram novos comentários, foram desconsideradas por não promoverem interação entre os indivíduos participantes.

Para interpretação dos sociogramas observam-se vértices com diferentes cores e tamanhos, que representam a participação dos envolvidos: alunos (excetuando-se o que mais participou) - vértices azuis; aluno que mais participou dentre os demais (aqui é considerado o número de participações, e não de interações efetivas) - vértice amarelo; tutor - vértice vermelho; professor formador - vértice verde. Vértices maiores e menores representam apenas uma escala tridimensional de organização dos sociogramas. Além disso, visualizam-se as ligações entre os vértices em forma de setas. O local onde a seta chega representa quem fez a réplica ao comentário. O local de onde a seta parte representa quem fez o comentário que gerou alguma interação.

\section{Resultados e Discussão}

Em todas as disciplinas avaliadas, observou-se que a participação dos alunos foi significativa e bastante representativa quando comparada à dos professores e dos tutores.

As disciplinas de Biologia Evolutiva e ESEM II apresentaram maior número de postagens e uma intermediária intervenção do tutor, enquanto a disciplina de ESEF teve o menor número de participações no total, embora tenha havido maior intervenção do tutor (Tabela 1). Diante desses resultados, pode-se destacar que, ao longo da vida acadêmica, os alunos, quando bem orientados, tornam-se mais maduros e empoderados, participando ativamente dos fóruns de interação, à medida que a intervenção do tutor se torna menos frequente.

Tabela 1:Análise da participação (número de participantes, de postagens do tutor, professor formador e alunos, e de postagens totais) em cada disciplina

\begin{tabular}{cccccc}
\hline Disciplina & Total de & Número de & Número de & Número de & Número \\
& Participante & postagens & postagens/ & postagens & total de \\
\hline
\end{tabular}




\begin{tabular}{|c|c|c|c|c|c|}
\hline & $\mathbf{s}$ & / tutor & alunos & $\begin{array}{c}\text { / professor } \\
\text { formador }\end{array}$ & postagens \\
\hline Microbiologia & 35 & 5 & 140 & 3 & 148 \\
\hline ESEF & 36 & 13 & 120 & 1 & 134 \\
\hline Biologia & 38 & 7 & 273 & 7 & 287 \\
\hline \multicolumn{6}{|l|}{ Evolutiva } \\
\hline ESEM II & 36 & 3 & 222 & 0 & 225 \\
\hline
\end{tabular}

A participação do professor formador foi considerada baixa quando comparada à do tutor. Tal percepção pode refletir o não preparo efetivo dos professores para o ensino a distância e, por vezes, a atuação desses professores limita-se aos momentos presenciais. Acredita-se que, para que os fundamentos da docência em ambiente virtual sejam efetivamente incorporados por esses profissionais, é necessário o desenvolvimento de novos saberes, tais como domínio das tecnologias de informação, reorganização do seu tempo, capacidade de trabalhar em esquipe, a escolha de metodologias e técnicas de ensino favoráveis às atividades de aprendizagem interativas e de colaboração entre os participantes da produção do conhecimento (SLOMSKI et al., 2016).

Ao analisar a Figura 1 percebe-se que, embora o aluno 13 tenha sido o que mais postou, não foi ele quem mais interagiu efetivamente e que o professor formador somente gerou uma interação na medida em que teve também somente uma participação. As interações efetivas concentraram-se no tutor, que postou 13 vezes, com 5 comentários geradores e 14 comentários respostas (lembrando que a soma do número de comentários geradores e respostas não coincide com o número de postagens, pois, concomitantemente, algumas postagens têm as duas funções, sendo, portanto, consideradas duas vezes). Ainda, observou-se que existe um grupo de indivíduos que depende da intermediação do tutor. 


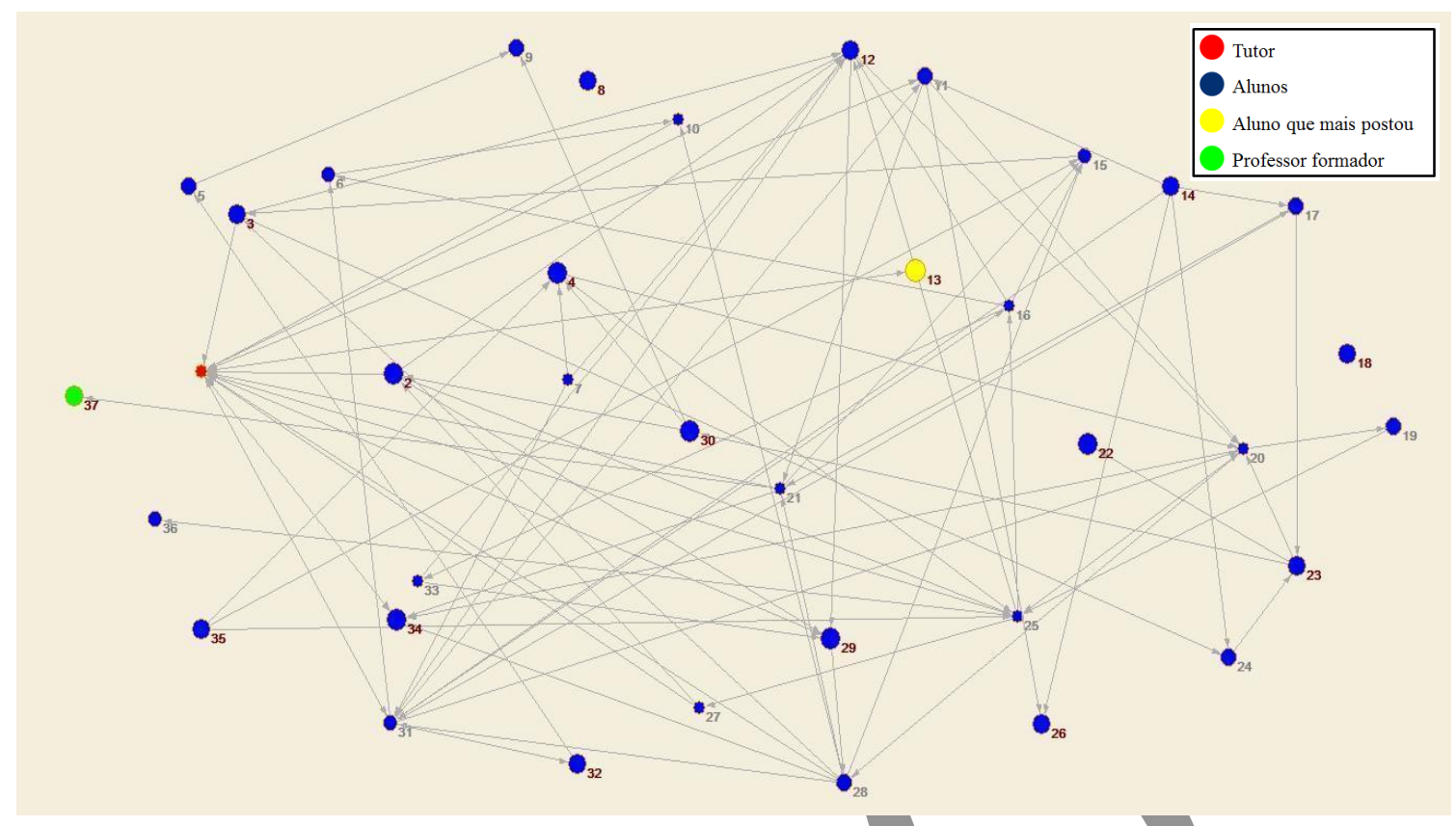

Figura 1:Sociogramaproduzido pelo software Pajek representando as interações efetivas da disciplina de ESEF, ocorrida no AVA do curso de Licenciatura em Ciências Biológicas/BIOEaD - UECE/UAB, polo de Beberibe-CE

Já na Figura 2 percebe-se que a dinâmica das relações muda e os alunos começam a se destacar com um grau de interação considerável. Há fluxos bidirecionais, como é o caso da interação entre os alunos 16 e 17, e o número de interações que os alunos estabeleceram entre si e com os tutores atingiu um nível mais elevado de colaboração quando comparados aos sociogramas das disciplinas do 50 semestre. 


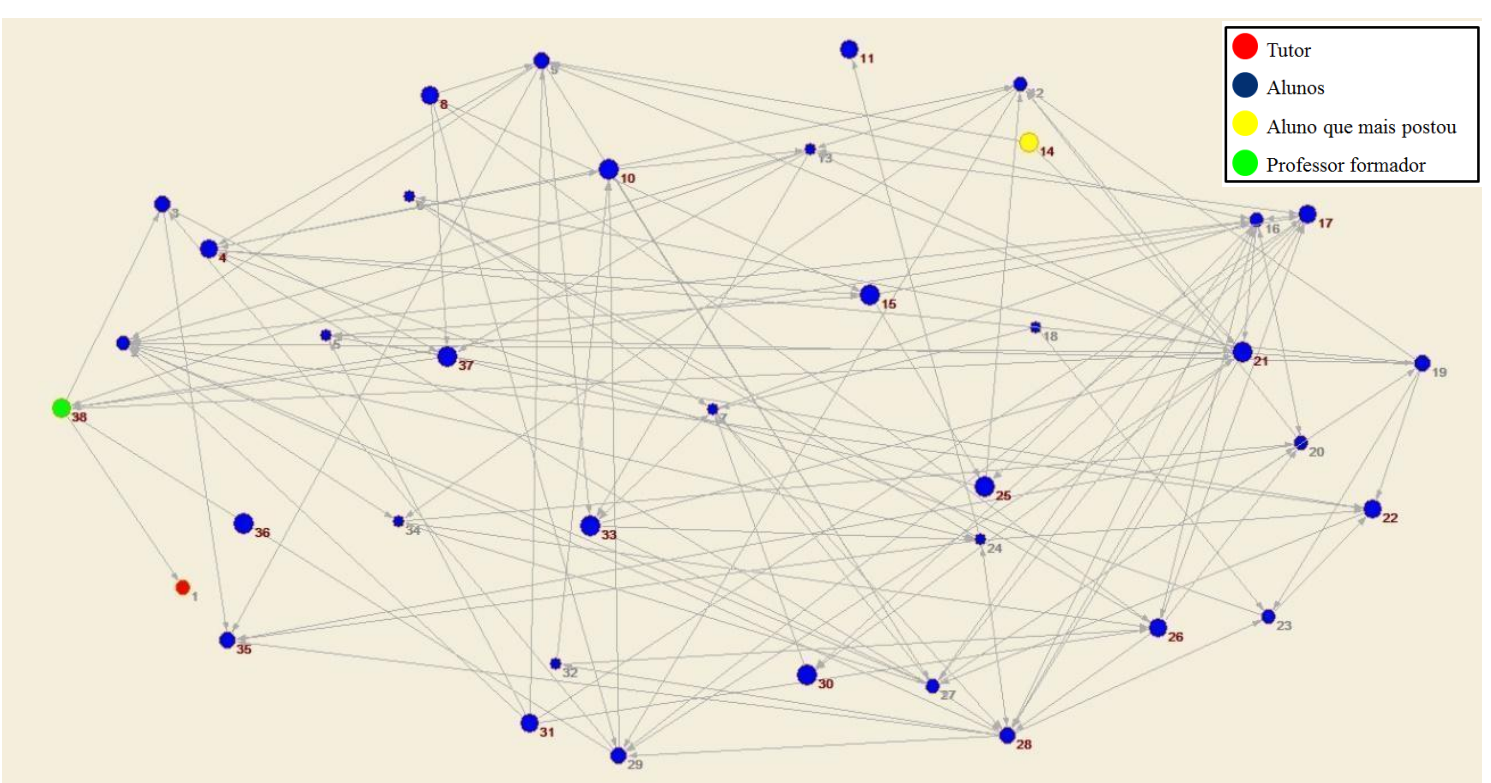

Figura 2:Sociograma produzido pelo software Pajek representando as interações efetivas da disciplina de Biologia Evolutiva, ocorrida no AVA do curso de licenciatura em Ciências Biológicas/BIOEaD - UECE/UAB, polo de Beberibe-CE

Observa-se que nas disciplinas dos semestres mais avançados, há uma menor dependência do tutor quanto à interação efetiva nos fóruns. Isso corrobora com a afirmação de Vidal e Maia (2010) de que a motivação gerada por tutores e por professores formadores, desde o início do curso, incentivam no aluno a autonomia, a criatividade, o raciocínio e a criticidade, colaborando com a ideia de que, em períodos mais avançados de sua formação, os alunos tendem a depender menos da participação do tutor, mesmo que de forma gradual a cada semestre.

Outro aspecto importante a ser destacado é que o número de interações efetivas foi sempre menor que o número de postagens conforme pode ser observado na Tabela 2. Isso significa que é importante estimular mais a interação quanto à qualidade das postagens. Aquelas elaboradas com mais argumentos e discussões críticas e reflexivas incentivam a participação dos demais indivíduos gerando interações efetivas (GRASSI \&SILVA, 2010).

Tabela 2: Análise do número de postagens e de interações efetivas em cada disciplina

\begin{tabular}{|c|c|c|c|c|}
\hline Disciplina & $\begin{array}{l}\text { Número de } \\
\text { postagens }\end{array}$ & $\begin{array}{l}\text { Número de } \\
\text { interações }\end{array}$ & $\begin{array}{c}\text { Interações } \\
\text { efetivas } \\
\text { /postagens }\end{array}$ & $\begin{array}{c}\text { Comentário } \\
\text { gerador (tutor } \\
\text { mais professor }\end{array}$ \\
\hline
\end{tabular}




\begin{tabular}{ccccr}
\hline & \multicolumn{2}{c}{ efetivas } & (\%) & formador) \\
\hline Microbiologia & 148 & 111 & 75,00 & 11 \\
\hline ESEF & 134 & 99 & 73,88 & 5 \\
\hline $\begin{array}{c}\text { Biologia } \\
\text { Evolutiva }\end{array}$ & 287 & 190 & 66,20 & 4 \\
\hline ESEM II & & & & 13 \\
\hline
\end{tabular}

As disciplinas em que ocorreu maior percentual de interações efetivas foram ESEM II e Biologia evolutiva, sendo observadas nelas maior número de comentários geradores realizados por tutores e professores formadores (Figuras 3 e 4), quando comparadas às outras duas disciplinas.

Na disciplina de Microbiologia (Figura 4), pode-se observar que nem sempre os alunos que mais postaram (vértices amarelos 27,28 e 31) foram os que mais apresentaram interações efetivas. Estas foram identificadas em maior número entre os alunos 31, 11 e 09, ainda que os alunos 27 e 28 também tenham tido um bom número de participações efetivas.

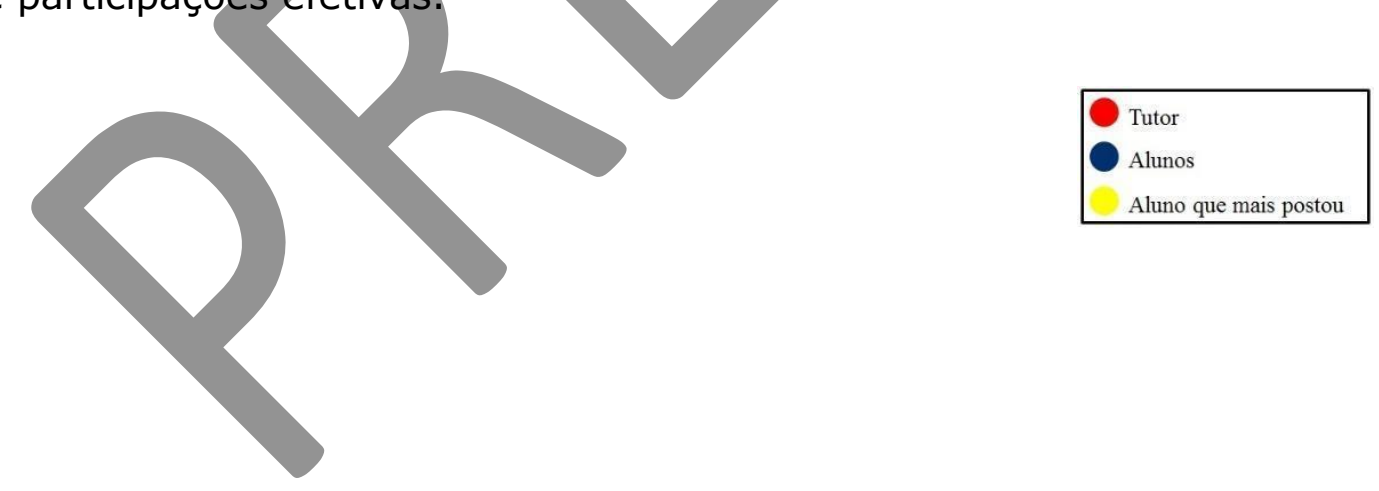

Figura 3:Sociograma elaborado pelo software Pajek representando as interações efetivas da disciplina de ESEM II, ocorrida no AVA do curso de Licenciatura em Ciências Biológicas/BIOEaD- UECE/UAB, polo de Beberibe-CE 


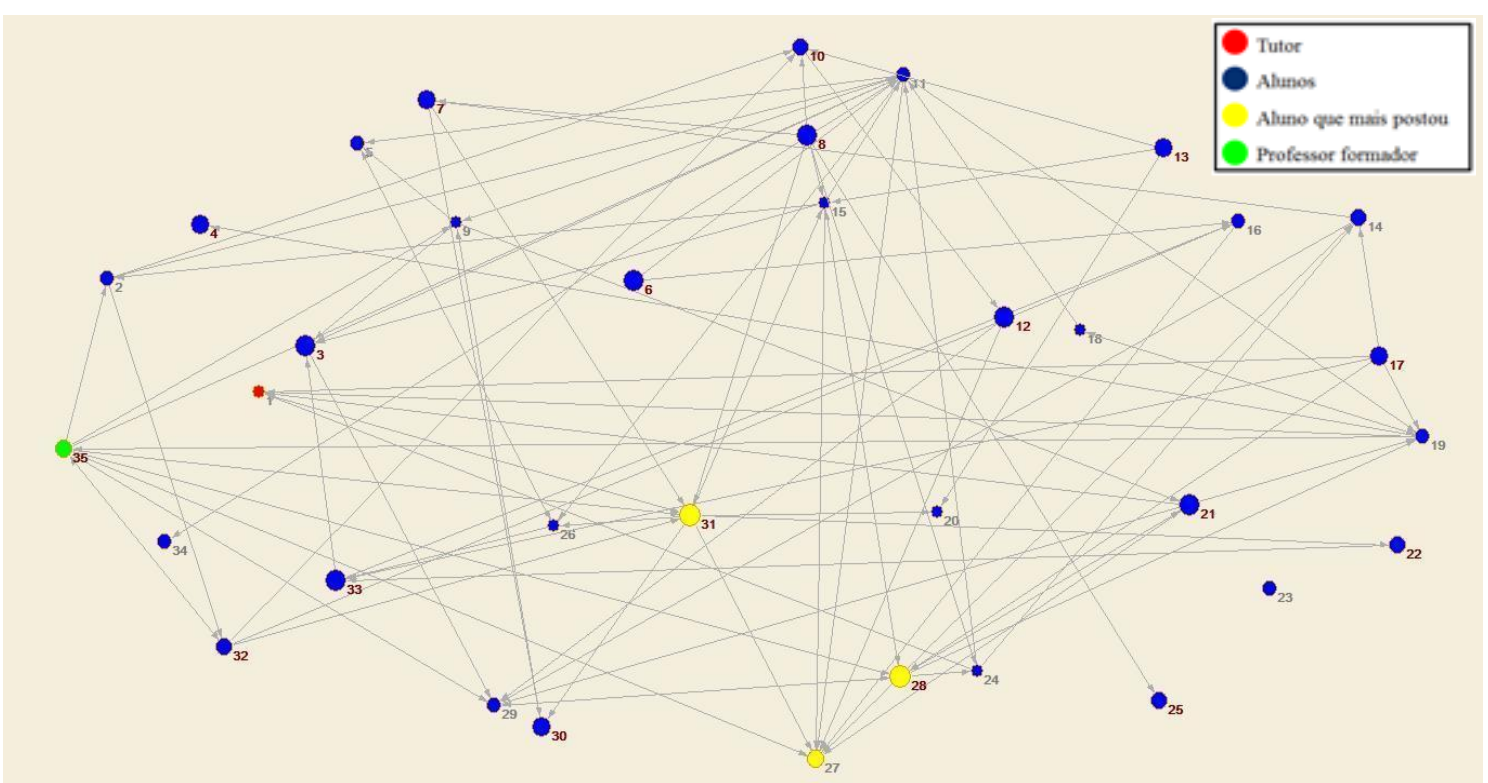

Figura 4:Sociograma elaborado pelo software Pajek representando as interações efetivas na disciplina de Microbiologia, ocorrida no AVA do curso de Licenciatura em Ciências Biológicas/BIOEaD - UECE/UAB, polo de Beberibe-CE

Pode-se inferir que a quantidade de postagens não significa bom ou mau desempenho. Para compreender essa afirmação, são apresentadas, no Quadro 2, a seguir, situações em que uma menor quantidade de postagens gerou um maior número de interações efetivas. Assim, a análise feita somente a partir da quantidade de postagens realizadas não deve ser parâmetro para avaliação, sendo necessário considerar as interações que geraram discussões (Quadro 2).

Quadro 2: Exemplos da relação entre a quantidade de postagens e a quantidade de interações efetivas em cada fórum analisado

\begin{tabular}{|c|c|c|c|c|c|}
\hline Disciplinas & Indivíduo & $\begin{array}{c}\text { Quantidade } \\
\text { de } \\
\text { postagens }\end{array}$ & $\begin{array}{c}\text { Comentários } \\
\text { gerados }\end{array}$ & $\begin{array}{c}\text { Quantidade } \\
\text { respostas }\end{array}$ & $\begin{array}{c}\text { de } \\
\text { interações } \\
\text { efetivas }\end{array}$ \\
\hline Microbiologia & $\begin{array}{c}\text { Professor } \\
\text { Formador }\end{array}$ & 3 & 10 & 2 & 12 \\
\hline $\begin{array}{c}\text { Biologia } \\
\text { Evolutiva }\end{array}$ & Aluno 14 & 21 & 7 & 0 & 7 \\
\hline
\end{tabular}


Fonte: Elaborado pelos autores.

Saliente-se que a quantidade de postagens não tem relação direta com a qualidade de interação. Na disciplina de Biologia evolutiva (ver Figura 2), por exemplo, observou-se que o aluno 14, que fez mais postagens teve 7 participações apenas respondendo ao questionamento central, não gerando, assim, interações efetivas com os demais participantes. Esse fato levou somente a 7 comentários norteadores de discussão e a nenhum comentário resposta, ou seja, ele não comentou ou respondeu outras postagens dos colegas.

Portanto, os sociogramas apresentados auxiliam na interpretação dos dados, já que são representações gráficas das relações existentes entre um grupo de indivíduos, além de ser um método de apresentação e de exploração de dados, possibilitando a identificação de fatos sociométricos e uma análise estrutural de uma comunidade (VAZ, 2009). Dessa forma, a leitura das relações torna-se mais fácil e mais clara, de forma que é possivel depreender uma apresentação sintética dos grupos, revelando a posição que cada indivíduo ocupa nele e como as inter-relações dos diversos indivíduos ocorrem.

Pôde-se observar também que alguns alunos estão mais centrais na rede, e outros, mais nas margens. Dessa forma, é possível traçar a trajetória de interação/participação do aluno e permite-se a comparação entre os sujeitos. Claramente observou-se nos sociogramas (Figuras 1 a 4) que, em todas as disciplinas, identificam-se os alunos que mais interagiram e os que formaram pontes de relacionamento (interações efetivas), bem como os que menos interagiram.

Por conseguinte, pondera-se que os sociogramas são imprescindíveis na identificação e no acompanhamento criterioso da participação dos alunos no processo de ensino-aprendizagem, já que ele permite a visualização daqueles que estão participando ou não das atividades e de que forma eles estão atuando (constantemente ou esporadicamente, efetivamente ou não), cabendo ao tutor e/ou professor formador chamar o aluno para atuar de forma ativa com comentários crítico-reflexivos, com recursos visuais (imagens, vídeos, esquemas entre outros) de forma contextualizada e com artigos científicos relacionados ao tema proposto.

Desta forma, o tutor, ciente de quais são esses alunos dentro da turma, poderia utilizar essa informação ao seu favor, melhorando a comunicação e a socialização 
entre eles (LIMA et al., 2014). Assim, esta análise se configura como uma ferramenta na gestão pedagógica do curso, sendo possível a adoção de medidas preventivas de acordo com as representações visuais, promovendo, entre os participantes do curso, maior socialização, principalmente para aqueles alunos que possuem dificuldades na interação, bem como identificar estudantes isolados, com possível risco de evasão, alunos com alto e com baixo desempenho, formar grupos, como também alunos com dificuldades de socialização.

Nesse caso, o sociograma configura-se como uma importante ferramenta para o desenvolvimento de uma boa gestão pedagógica do curso, já que proporciona uma visão mais individualizada do aluno, direcionando ações para sanar as dificuldades que interferem no bom desempenho dos discentes.

\section{Considerações finais}

Ao analisar a dinâmica das relações interacionais entre alunos, professores e tutores de um curso de graduação na modalidade a dístância, conclui-se que, a elaboração de sociogramas a partir de fóruns de discussão permite identificar os alunos que precisam ser mais incentivados a participar das atividades e auxiliam o tutor e o professor formador na condução da turma, possibilitando a identificação dos alunos que estão ou não contribuindo de forma efetiva com discussões críticas e reflexivas, de forma a favorecer um acompanhamento individualizado.

Observou-se também que, quando bem orientados por seus tutores, o aluno gradativamente se torna mais autônomo ao longo do curso, participando de forma mais ativa quantitativa e qualitativamente de fóruns de discussão, o que se reflete em um maior número de postagens e de interações entre os alunos.

Por fim, destaca-se que o uso de sociogramas orientam como tutores e professores formadores podem tomar atitudes com seus alunos, configurando-se numa importante ferramenta pedagógica e de gestão nos cursos de graduação a distância, promovendo maior qualidade ao processo de ensino-aprendizagem.

\section{Referências}


ABEGG, I.;BASTOS, F. P. \&MULLER, F. M. (2010). Ensino-aprendizagem colaborativo mediado pelo Wiki do Moodle. Educar em Revista, 38(1), 205-218. Disponível em <file://C:/Users/Lydia\%20Pantoja/Downloads/13129-73032-1-PB.pdf>.

ALENCAR, M. A. S. \&NETTO, J. F. M. (2011). Improving Cooperation in Virtual Learning Environments Using Multi-Agent Systems and AIML. In: Proceedings 41th Frontiers in Education Conference (FIE). Rapid City, South Dakota, USA, 1, 17131719.

BELUCE, A. C. \&OLIVEIRA, K. L. (2016). Escala de estratégias e motivação para aprendizagem em ambientes virtuais. Rev. Bras. Educ., 21(66), 593-610. 2016. Disponível em: <http://dx.doi.org/10.1590/S1413-24782016216631>.

CARVAlHO, A. D. S. de;OliveirA, V. I.;GuedeS, A. C. B. S.\& Martins, J. L. (2017). Gestão da Aprendizagem, Proatividade e Autonomia dos Discentes: Novas Práticas. Aturá - Revista Pan-Amazônica de Comunicação, 1(3), 175-188. Disponível em<https://sistemas.uft.edu.br/periodicos/index.php/atura/article/view/4096>.

CORTElAZZO, I. B. C. (2010). Prática Pedagógica, Aprendizagem e Avaliação em Educação a Distância.2 ed. Curitiba: Ibpex.

DILLENBOURG, P. (2003). Virtual Learning Environment. Disponível em: <http://tecfa.unige.ch/tecfa/publicat/dil-papers-2/Dil.7.5.18.pdf> .

GRASSI, D. \&SILVA, J. M.(2010). A mediação pedagógica em fóruns de discussão nos cursos virtuais. Revista Novas Tecnologias na Educação, 8(1), 1-10. Disponível em:<file:///C:/Users/Lydia\%20Pantoja/Downloads/15197-53298-1-PB.pdf>.

LIMA, D.;GADELHA, B., NETTO, J. F. \&BREMGARTNER, V. (2014).Moodle Groups: Um aplicativo para identificar as relações sociais entre alunos em Ambientes Virtuais de Aprendizagem. In: SBSC 2014 Proceedings-Ongoing Research, Curitiba/PR. 6(9), 142148.

NOORY, W.;MRVAR, A. \&BATAGELJ, V. (2005).Exploratory network analysis with Pajek. Cambridge: Cambridge University Press.

PRIMO, A. (2007).Interação mediada por computador.Porto Alegre: Sulinas.

SANTOS, P. K. (2015). Permanência na graduação à distância na perspectiva dos estudantes: um estudo a partir da experiência do projeto alfa guia. Tese (Doutorado 
em Educação) - Pontifícia Universidade Católica do Rio Grande do Sul, Porto Alegre, $223 \mathrm{p}$.

SANTOS, S. do N., Baez, M. P.\&Souza, V. L. R. (2018). Gestão da Educação a Distância, Material Didático, avaliações na AVA de aprendizagem: crenças e "verdades". Revista Multidisciplinar do Amapá, v. 1, n. 1, 63-80. Disponível em:<file://C:/Users/Lydia\%20Pantoja/Downloads/187-1256-1-PB.pdf>

SLOMSKI, V. G., ARAÚJO, A. M. P.,CAMARGO,A. S. S. \&WEFFORT, E. F. J. (2016).Tecnologias e mediação pedagógica na educação superior a distância. Journal of Information Systems and Technology Management.v. 13, n. 1,131-150.Disponível em: <http://www.scielo.br/pdf/jistm/v13n1/1807-1775-jistm-13-1-0131.pdf>.

VAZ, J. G. (2009). A Construção dos Sociogramas e Teoria dos Grafos. Revista Brasileira de Psicodrama. v. 17, n. 1, p.67-78. Disponível em: <http://pepsic.bvsalud.org/pdf/psicodrama/v17n2/a06.pdf>

VIDAL, E. M. \&MAIA, J. E. B.Introdução à Educação a Distância. Fortaleza: RDS, 2010. YIN, R. K.Estudo de caso: planejamento e métodos. Porto Alegre: Bookmann, 2010.

\section{COMO CITAR ESTE ARTIGO}

ABNT: PAIXÃO, Germana Costa et al. Dinâmica das Relações Interacionais em Fóruns de Discussão em um Curso de Graduação a Distância Representada por Sociogramas. EAD EM FOCO, [S.I.], v. 8, n. 1.2018. ISSN 2177-8310.

APA: Paixão, G., Souza, R., Lima, F., Pinheiro, J., \& Pantoja, L. (2018). Dinâmica das Relações Interacionais em Fóruns de Discussão em um Curso de Graduação a Distância Representada por Sociogramas. EAD EM FOCO, 8(1) doi:https://doi.org/10.18264/eadf.v8i1.741 